\title{
- $U$
}

Clarissa Alcântara* | Universidade Federal de Santa Catarina

Resumo: No contexto do cinqüentenário do Concretismo no Brasil, este texto pretende revisitar o repertório que alicerçou o Movimento da Poesia Concreta e que, desde sua gênese até hoje, deixou perguntas irrespondidas.

Palavras-chave: poesia concreta, poesia experimental, Noigrandes.

\author{
Enquanto não mudarmos de princípio de \\ avaliação, enquanto substituirmos os velhos \\ valores por novos, apenas assinalando novas \\ combinações entre as forças reativas e a vontade \\ de nada, nada mudou, continuamos sempre \\ sob o reino dos valores estabelecidos. \\ Gilles Deleuze, Nietzsche, 1965. \\ ... esse inversor do duplo é, por certo, o \\ nível de mistério de minha vida.
}

Wlademir Dias-Pino

* Doutora em Teoria Literária e Pós-doutoranda do Núcleo de Pesquisa em Informática, Literatura e Lingüística (NUPILL) / UFSC. 
Q que é poesia concreta, afinal? Por que poesia concreta? De onde saiu? Aonde vai? Quem a desbrava? Quem a assina? Quem a assume? O que dela e nela se inventa? E a poesia visual? Seria a poesia concreta uma de suas ramificações? Mas e a poesia experimental: não seria este o conceito mais amplo? E o poema/ processo, uma radicalidade que esfarinha cada estrutura/palavra dessas que nasce, porque decididamente faz a distinção e é Poema - linguagem - e não Poesia língua?

Perguntas que se querem impertinentes e refletidas num plano em que não estão resolvidas, apenas dissolvidas e remetidas para o vazio de onde surgiram. Talvez possam soar um tanto descabidas e pretensiosas ao meio artístico-literário que comemora os 50 anos do concretismo brasileiro e marca, como momento histórico de seu surgimento, o ano de 1956, com a I Exposição Nacional de Arte Concreta, no MASP. Meu breve intuito, de claro risco - traço mais de subtração do que de união -, é revirar a fantasia crítica do que foi estabelecido neste repertório. Retirar dos escombros o que foi rejeitado e soterrado na construção ficcional de seus registros.

Esta é uma daquelas histórias que carrega na matriz dos fatos ocorridos a redundância das marcas dos graves equívocos, precipitando no esquecimento a parte incômoda do arquivo. Se um estudante, um pesquisador, ou um simples interessado nos movimentos literários da vanguarda brasileira, nascido, como eu, lá pelos meados dos anos 60, dispuser-se a buscar informações, documentos, registros desta história que margeava o país desde a década de 40, inflando-se no eixo-centro nos anos 50 e desafiando forças e dominâncias por todo o território no sufoco dos 60 , vai se deparar, sem dúvida, com sérias e danosas perfurações, retalhaduras de uma outra astuciosa ditadura, a da má política literária brasileira.

O Grupo Noigandres, ${ }^{1}$ formado por Haroldo de Campos, Augusto de Campos e Décio Pignatari, intercepta os fatos e declara lançado oficialmente o Movimento da Poesia Concreta, assinando, na história da literatura, a autoria do que foi declarado como "o mais controverso movimento de poesia

\footnotetext{
1. "Desde 1952, os jovens intelectuais paulistas vinham procurando um novo caminho através de uma revista chamada Noigandres, palavra tirada de um poema de Ezra Pound e que não significa nada". GONZAGA, Sergius. Literatura contemporânea - Poesia concreta. Disponível em: <http://educaterra. terra.com.br/literatura/litcont/2003/04/22/001.htm>. Acesso em 13 fev. 2006.
} 
vanguardista brasileira: o concretismo”. ${ }^{2}$ Tal controvérsia, contudo, não estava na proposta inventiva de uma poesia racional que se dispunha a explorar às raias a estrutura da palavra, como um objeto dinâmico, visual e matematicamente construído, mas sim, na problemática da liderança requerida para si, "a ferro e fogo, e até contra os fatos", ${ }^{3}$ como testemunha o crítico Álvaro de Sá. Hoje, falar em poesia concreta é falar em idioma noigandres. Wlademir Dias-Pino, o mais independente poeta entre os fundadores da poesia concreta - "poeta que sempre teve como constante o abrir mão como uma assinatura de não querer reter coisa alguma” ${ }^{4}$ - é quem, hoje, deliberadamente, esclarece os fatos:

Eu não entendo que o Grupo Noigandres tenha lançado oficialmente a Poesia Concreta, porque ela só aparece pública na referida exposição que é composta por mais três pessoas. ${ }^{5}$ O aparecimento de um movimento de poesia, dentro de uma exposição de arte concreta, torna-se ainda mais grave, pela não-existência de um manifesto. Como se sabe, o Plano-Piloto só apareceu dois anos depois e mais tarde recebeu nova versão, atualizandose às circunstâncias do momento.

Declarados "cultos e sofisticados", os poetas do grupo Noigandres sabiam muito bem reconhecer a necessidade oportuna do acaso, como bons jogadores de um lance de dados. O que lhes faltava era, sem dúvida, a compreensão da afirmação do múltiplo, onde aparece generosa a alegria prática do diverso. É pela comemoração desse festim dourado que vale a declaração de mais um persistente pesquisador das vanguardas:

2. Idem.

3. SÁ, Álvaro R. de ; SÁ, Neide S. de. Metacrítica de Augusto de Campos. Piauí: Editora Lava-Roupa, 1979, p. 13.

4. SANTOS, João Felício dos. "No pixe de machado penumbra, à guisa de puxação". In: Álvaro de Sá; Neide de Sá. op. cit., p. 6.

5. A saber: Wlademir Dias-Pino, Ferreira Gullar e Ronaldo Azeredo. O Planopiloto da poesia concreta, publicado na revista Noigandres 4, em 1958, escrito à revelia das outras direções que formavam o concretismo, foi decisivo para o combate público de Ferreira Gullar aos poetas paulistanos. Seu afastamento definitivo marca-se meses depois, com a publicação do "Manifesto Neoconcreto", no Jornal do Brasil.

6. DIAS-PINO,Wlademir. Comentário escrito em março de 2006 na versão (primeira) do projeto Acervo eletrônico Wlademir Dias-Pino: o poema máquina. Projeto ainda em elaboração pelos núcleos de pesquisa da UFSC, UFMG e Universidade Presbiteriana Mackenzie/SP. 
O eixo e a roda: $v .13,2006$

Disponível em: http://www.letras.ufmg.br/poslit

\begin{abstract}
A importância de 1956 para a história da literatura brasileira pode ser registrada mediante três episódios capitais: o lançamento da poesia concreta, a publicação de Grande sertão: veredas e o surgimento de A ave, de Wlademir Dias-Pino, livro que se liga(va) às virtualidades gráficas e verbovisuais do concretismo, porém que, como veremos, apontava para um desdobrar novo nas aventuras composicionais da própria poesia concreta. E o que é $A$ ave? Um livro que, pela primeira vez no Brasil, assume radicalmente a sua condição estrutural de livro-fabricado-como-um-objeto/poema, e não como um mero suporte ou invólucro de poemas e textos literários.
\end{abstract}

$A$ ave, segundo Dias-Pino, foi iniciada no Movimento Intensivista em Cuiabá, no ano de 1948, trazendo em sua fisicalidade funcional, sempre em processo, a invenção do primeiro livro/poema da história da literatura, feito para uma leitura de manuseio: "leitura que se faz durante os mais diversos usos exploratórios de um mesmo objeto: o livro". " $A$ ave nunca se completará, exceto na mão de cada consumidor", diz Álvaro de Sá, respondendo a Augusto de Campos o qual insiste em dizer que o poema $A$ ave foi completado em $1956 .{ }^{9}$ Somente com intuito histórico as datas se registram e os fatos se documentam, mas sempre como matéria ficcional; do contrário, o que resta é a continuidade/ descontinuidade da experiência posta à prova. O que, talvez, tenha sido difícil para Augusto de Campos sustentar é, de fato, esta extraordinária invenção que $A$ ave traz em sua fisicalidade intrínseca e que, de forma precursora, atinge em rigor aberto aquilo que a poesia concreta buscava recuperar: a materialidade do poema e a sua mais radical autonomia, o contra-estilo; portanto, não mais a marca redundante do autor, não mais a estrutura mas o processo, não mais a palavra mas o projeto, não mais a tradução mas a versão, não mais a lingua mas a linguagem. Álvaro e Neide de Sá, em sua Metacrítica de Augusto de Campos, testemunham: " $A$ ave, com seus inúmeros caminhos inventivos, questionava a própria poesia concreta como coisa acabada, trazendo a necessidade de estabelecer a leitura do espaço de inscrição e aí fundamentava e tornava-se precursor do movimento do poema/processo". ${ }^{10}$

7. CIRNE, Moacy. Vanguarda: um projeto semiológico. Rio de Janeiro: Ed. Vozes, 1975, p. 29.

8. Idem, p.32

9. SÁ, Álvaro R. de ; SÁ, Neide S. de, op.cit., p. 33.

10. Idem, p. 47. 
$A$ ave, objeto/poema e não poema/objeto, traz mais do que a "explicitação da materialidade da linguagem" (como pretendiam tecnicamente os "poetas concretos", na visão de Augusto de Campos, buscando uma "radicalização e condensação dos meios de estruturação do poema" ${ }^{11}$ ): é sua fisicalidade funcional de objeto de leitura autoconsumível que faz dele o poema. A partir de um conjunto de matrizes, cria versôes em processo e tem a propriedade de oferecer diferentes direções de leitura em permanente movimento interativo "um poema que codifica letras em novos signos geométricos e que possui chave vocabular para permitir a leitura de suas variações". ${ }^{12}$ A linguagem verbal é elemento de redundância e seu uso é apenas um orientador para as leituras não-verbais, um retardador de leitura, define Wlademir Dias-Pino. Um livro que recebeu tratamento de máquina "com suas folhas soltas, perfuradas, cortadas, codificadas em séries, quase a ponto de ser computador de bolso", ${ }^{13}$ com a intenção de criar uma leitura sem intervalos, uma "leitura a partir dos códigos pela informação geometrizada - até atingir a velocidade da leitura eletrônica ou contínua". ${ }^{14}$ No fim dos anos 40, um poema é fundador de linguagem: está posto o desafio de uma forma revolucionária, diretamente ligada à realidade veloz das novas tecnologias. A máquina é o poema.

"Sem forma revolucionária não há arte revolucionária" - o grupo Noigandres acrescenta ao seu "manifesto revisado" a afirmação de Maiakovski. Ela é estratégica para quem tem "o intento de criar novas condições operacionais para a elaboração do poema, no quadro da revolução tecnológica". ${ }^{15}$ Passados 50 anos, é possível constatar que o plano-piloto da Poesia Concreta, tão comprometido com o espaço gráfico como agente estrutural, não encontra forma

11. Campos, Augusto de. Augusto de Campos - Site Oficial - UOL. Disponível em: $<$ http://www2.uol.com.br/augustodecampos/poesiaconc.htm $>$ . Acesso em: 2 fev. 2006.

12. A Idem, p. 57.

13. SÁ, Álvaro de. Vanguarda - produto de comunicação. Rio de Janeiro: Editora Vozes, 1975, p. 104.

14. DIAS-PINO, Wlademir. Comentário escrito sobre o projeto Acervo eletrônico Wlademir Dias-Pino: o poema máquina, março de 2006.

15. CAMPOS, Augusto de. Textos. Disponível em: < http://www2.uol.com.br/ augustodecampos/yaleport.htm>. Acesso em 2 fev.2006. Resposta à pergunta de K. David Jackson, Eric Vos e Johanna Drucker: "Quais são os fundamentos teóricos que distinguem as suas obras das dos precedentes históricos ou dos contemporâneos?". 
possível para atingir seu objetivo no contexto das novas mídias. O poema concreto é um objeto fechado em si mesmo que comunica somente sua própria estruturaconteúdo, necessariamente autoral. Faz-se interativo até o limite imposto pelo uso de seu material - a palavra - como sistema estruturante sempre regulador. Poemas concretos em meio eletrônico encontram a função de animações figurativas de grafismo sonoro, a exemplo do poema-bomba (1983 - 1997), de Augusto de Campos, cuja fisicalidade operacional está sob o domínio da língua, da escrita, do estilo (escolha estatístico-preferencial nas estruturas armazenadas), ${ }^{16}$ sem nunca chegar ao realismo total da explosão tipográfica, a criar nova linguagem, a ser o poema.

Cinqüenta anos depois da I Exposição Nacional de Arte Concreta, o objeto/poema de Wlademir Dias-Pino, mesmo auto-exilado por força da ditadura Noigandres, continua espantando pela radicalidade e - como continuidade radical da poesia concreta - o movimento do poema/processo deixa parâmetros conceituais precisos extraídos de sua prática indissociável e permanente. O poema/processo, mesmo com sua parada tática enquanto movimento em 1972, avança ao criare dar condições a processos táteis, móveis, múltiplos, plurais, de força ativa e não reativa. Experiência posta à prova no instante em que o poema afirma sua diferença em relação à poesia e aponta para um outro nível de escritura/leitura feita com o processo (o situar da invenção informacional), e não com palavras. Leitura produtiva sempre inédita para um leitor ativo: enquanto testa a funcionalidade do poema, inventa a realidade e executa a própria versão.

Teia gráfica rigorosamente aberta, campo de possibilidades - outras tantas versões se tornam questão. "À virada do tempo, diz Blanchot, corresponde o poder de se tornar questão, palavra que, antes de falar, questiona pela maneira de ser da escrita". ${ }^{17}$ Escrita fora do discurso, fora da linguagem? O que é objeto? E o livro, afinal? O que pode o corpo?

16. DIAS-PINO, Wlademir. Processo:linguagem e comunicação. Petrópolis: Vozes, 1971. Antologia de poemas e manifestos do movimento do poema-processo.

17. BLANCHOT, Maurice. A conversa infinita - a palavra plural. São Paulo: Ed. Escuta, 2001, p. 41 
Disponivel em: http://www.letras.ufmg.br/poslit

Abstract: In the context of the 50th anniversary of the Concretism in Brazil, this text intends to revisit the repertory that was the foundation of the Movement of the Concrete Poetry and, which, since its genesis until today, has left some unanswered questions.

Key words: concrete poetry, experimental poetry, Noigrandes. 